\title{
Open Perilunate Fracture Dislocation with Lunate Extrusion: A Case Report and Literature Review
}

\author{
Mário Baptista ${ }^{a} \quad$ Elisabete Ribeiro $^{a} \quad$ Melanie Ribau $^{a} \quad$ Nuno Vieira Ferreirab, c \\ Pedro Varanda ${ }^{a}$ d Luís Filipe Rodrigues ${ }^{a}$ \\ aDepartment of Orthopedic Surgery and Traumatology, Hospital de Braga, Braga, Portugal; \\ bepartment of Orthopedic Surgery and Traumatology, Hospital Santa Maria Maior, Barcelos, \\ Portugal; 'Trofa Saúde Group, Porto, Portugal; dSchool of Medicine and ICVS/3B's - PT \\ Government Associate Laboratory, University of Minho, Braga, Portugal
}

\section{Keywords}

Lunate enucleation - Lunate extrusion - Open injury · Perilunate injury · Perilunate fracturedislocation

\begin{abstract}
Perilunate injuries with lunate extrusion are extremely rare, representing an extreme subgroup of the Mayfield type 4 spectrum, with prognosis and management remaining controversial. We present a 45-year-old man with an open type 4 perilunate fracture dislocation, with lunate extrusion through the volar skin. Despite emergent treatment with open reduction and internal fixation, lunate and scaphoid proximal pole avascular necrosis developed. However, the overall functional outcome was satisfactory for daily activities at 30 months followup, with substantial improvement in the range of motion after hardware removal. To our knowledge, this is the third reported case of an open perilunate injury with lunate extrusion in the literature.
\end{abstract}

\section{Introduction}

Perilunate lesions, first described by Malgaigne [1], are high-energy injuries with complex carpal instability [2], involving around 7\% of all the traumatic lesions of the carpus [3]. In 1980, Mayfield described a continuum of 4 stages [4], in which progressive ligament and bone dissociation occur [2]. These may be isolated perilunate dislocations (PLDs) or perilunate fracture dislocations (PLFDs), with scaphoid fractures seen in $65 \%$ of cases [1, 2]. Herzberg 


\section{Case Reports in Orthopedic Research}
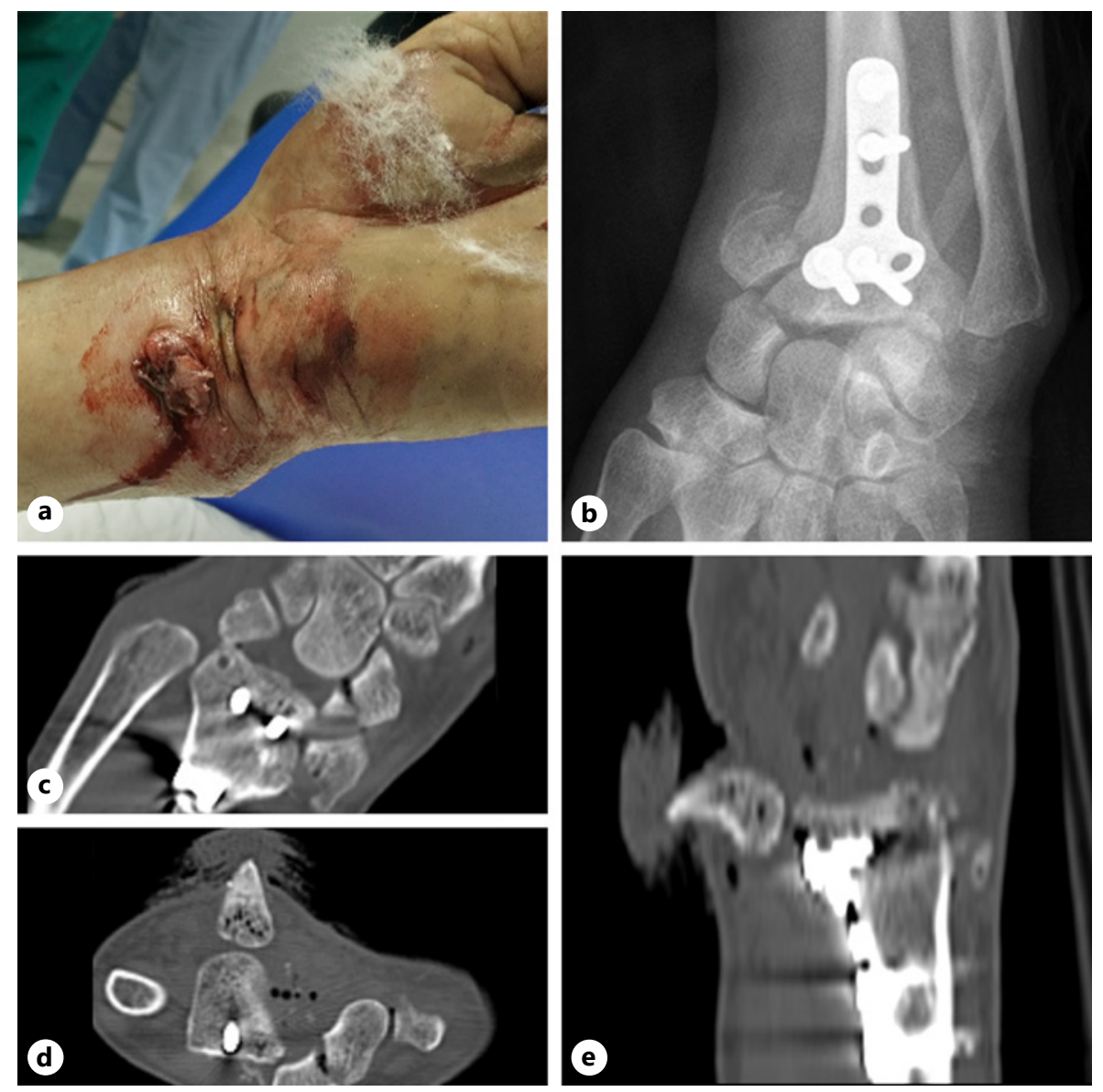

Fig. 1. Preoperative gross depiction of injury, showing the open wound with exposed lunate (a); preoperative anteroposterior radiograph of the left wrist, demonstrating a transradial-styloid transscaphoid perilunate fracture dislocation (b); preoperative CT scan images, demonstrating the radial styloid and scaphoid fractures in the coronal plane (c) and the open lunate extrusion through the volar skin in the axial (d) and sagittal planes (e).

reviewed 166 cases and found that transscaphoid PLFDs were the most common pattern, though only $20 \%$ had a volarly dislocated lunate [5]. Although posttraumatic arthritis can be expected in the majority of patients, most cases are clinically well-tolerated $[1,3]$.

Rarely, the lunate migrates volarly with complete ligamentous detachment and impaired vascularization, greatly increasing the risk of avascular necrosis (AVN) [6]. Few reports in the literature describe well-defined lunate extrusion or enucleation [7-17], of which only 2 were open injuries $[9,14]$. We present a case of an open Mayfield type 4 PLFD with lunate extrusion through the volar skin.

\section{Case Presentation}

A 45-year-old male electrician presented to the emergency room with a severe injury to the left wrist after a fall from height with forced hyperextension (nondominant hand, previously treated with a volar plate for a distal radius fracture 20 years ago). On examination, there was gross deformity of the left wrist and a volar wound $(15 \times 10 \mathrm{~mm})$ proximal to the wrist crease, with evident bone exposure (Fig. 1a). No neurovascular 
Case Reports in Orthopedic Research
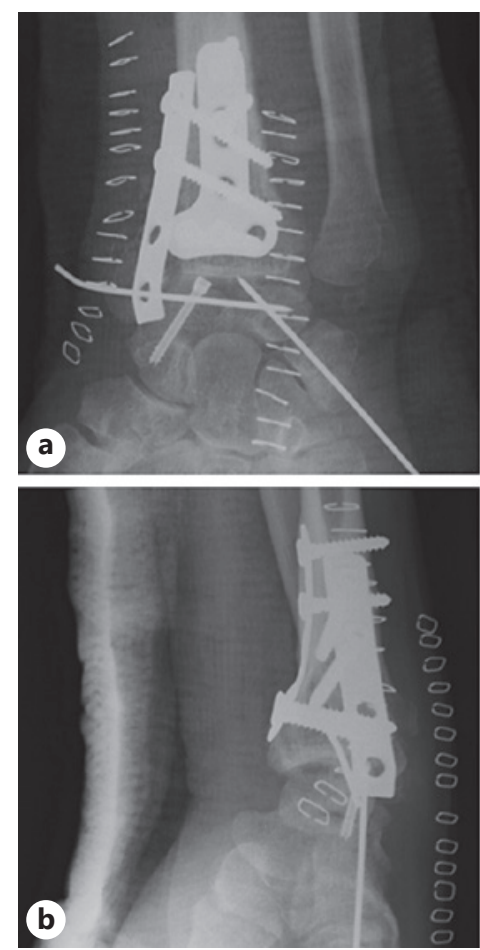

Fig. 2. Left wrist anteroposterior and lateral radiographs: postoperative, demonstrating a malpositioned scaphoid screw (a, b); at 12 months follow-up (c); at 30 months follow-up, with signs of lunate and proximal scaphoid avascular necrosis (d); and after hardware removal $(\mathbf{e}, \mathbf{f})$.

deficits were noted. Initial management included temporary splinting and intravenous antibiotic. Plain radiographs and computed tomography scan revealed an open Mayfield type 4 transradial-styloid transscaphoid PLFD, with lunate extrusion through the volar wound (Fig. 1b-e) [4].

Emergent surgery was promptly performed after adequate irrigation, using a combined approach. Through a volar approach across the open wound, an extended carpal tunnel release was performed. The extruded lunate was found isolated, with complete ligamentous attachment disruption. It was then reduced onto the radius lunate fossa, followed by repair of the volar capsule rent with nonabsorbable sutures. A subsequent dorsal approach was performed, with a ligament-sparing dorsal capsulotomy [18] and neurectomy of posterior interosseous nerve. The scapholunate and lunotriquetral ligaments were irreparable, with no remnants remaining. Scaphoid fracture was anatomically reduced and fixed with a Herberttype screw, followed by scapholunate and lunotriquetral pinning after correct scapholunate alignment was obtained. The radial styloid was reduced and fixed with a buttress plate. Postoperative radiographs revealed a malpositioned scaphoid screw (Fig. 2a, b), and surgical revision was proposed but refused by the patient. A dorsal splint was maintained for 8 weeks, with Kirschner wires removal at 6 weeks. Unrestrained wrist mobility and physical rehabilitation initiated afterward.

At 12-month follow-up, radiographic evaluation revealed a scaphoid nonunion with a scapholunate angle of $70^{\circ}$. Neither osteoarthritis nor collapse was evident, with a normal carpal height ratio of 1.65 [19] (Fig. 2c). On the Visual Analog Scale for pain, the patient attributed 2 of 10 and reached 32 points on the Disabilities of the Arm, Shoulder and Hand (DASH) questionnaire. Wrist range of motion was evaluated with a classic goniometer: flexion $60^{\circ}$, extension $20^{\circ}$, radial deviation $10^{\circ}$, and ulnar deviation $10^{\circ}(67 \%, 33 \%, 33 \%$, and $38 \%$ 
of contralateral side, respectively). Strength parameters were obtained with a dynamometer (Lafayette Hand-Held Dynamometer): grip strength 8.8N and pinch strength $8.2 \mathrm{~N}$ (80 and $97 \%$ of contralateral side, respectively).

By 30 months of follow-up, the patient reported progressive loss of motion of the left wrist, despite having no increase in pain. Radiographs revealed signs of lunate and scaphoid proximal pole AVN, with mild radiocarpal osteoarthritis and collapse (Fig. 2d). Hardware removal was then performed (Fig. 2e, f). The patient reported a significant increase in wrist range of motion afterward, with minimal pain performing common daily activities and good overall satisfaction on last evaluation.

\section{Discussion}

Lunate extrusions represent an extreme subgroup of the type 4 spectrum, lacking evidence and guidelines, and have been proposed as an additional fifth type to the Mayfield classification [16]. Due to the additional volar ligamentous attachment disruption, there is a total absence of vascularization to the lunate, and the risk for AVN greatly increases [6].

To the best of our knowledge, there are twelve reports in the literature of PLD/PLFD with well-documented isolated lunate extrusion and complete ligamentous detachment, which are detailed in Table 1. All patients were male, ranging from 19 to 48 years old, who suffered a high energy trauma to the wrist. The most common injury pattern was a transscaphoid PLFD, and only 2 patients $(17 \%)$ had open injuries. Regarding treatment, open reduction and internal fixation (ORIF) was performed in 8 cases (67\%), while a primary proximal row carpectomy (PRC) was opted in 4 (33\%). Intrinsic ligaments repair was only possible in half of the ORIF cases, reflecting soft tissue injury severity. The immobilization period was diverse, averaging 9.2 and 5.8 weeks for ORIF and PRC, respectively. As the lunate becomes avascular after such an injury, it should be expected that all ORIF attempts would lead to inevitable AVN [10]. In contrast, lunate osteonecrosis was only observed in 3 patients (38\%) - with 2 of those requiring a second surgery for wrist arthrodesis. Nonetheless, among the 5 patients with a surviving lunate, 2 still developed important radiocarpal osteoarthritis over 144 and 36 months, while those with no reported complications had only 6-12 months of follow-up. We believe that such small follow-up periods are insufficient to draw optimistic conclusions from and should not make an argument for ORIF efficacy.

Though initially reserved for chronic cases or as a salvage procedure after failed ORIF, some authors have proposed PRC as a first-line treatment for acute PLFD, where AVN or severe carpal instability is expected $[8,20]$. For arthritis treatment, PRC has durable results, with a low failure rate and good functional wrist motion expected at long-term follow-up [21-23]. However, worse outcomes have been observed with younger patients and those with heavy manual labor. A study comparing primary ORIF and PRC in acute PLFD observed that medium-term results were equivalent between groups, apart from moderate better extension with ORIF [20]. In the cases summarized in Table 1, 4 patients were treated with primary PRC. This group had reduced immobilization times, and all patients reported a painless wrist at the final follow-up, with no reported complications. In retrospect, PRC might have been a viable option for our patient as the probability of AVN was extremely high even if a successful ORIF had been obtained.

There are a few reports of extrusion of lunate and scaphoid as a unit, where ORIF appears to provide good results. We believe these to be different injuries, with distinct prognosis implications as the intact scapholunate ligament may allow for lunate revascularization after scaphoid healing occurs $[24,25]$. Though the ability of the lunate to recover from transient vascular compromises has been well-described [25], there is still no explanation for how the vascularization is restored after a complete ligamentous detachment.

\section{Karger'}


Case Reports in Orthopedic

Research
Case Rep Orthop Res 2021;4:210-216 DOI: 10.1159/000518209 (c) 2021 www.karger.com/cio

Baptista et al.: Open Lunate Extrusion: Case Report and Literature Review

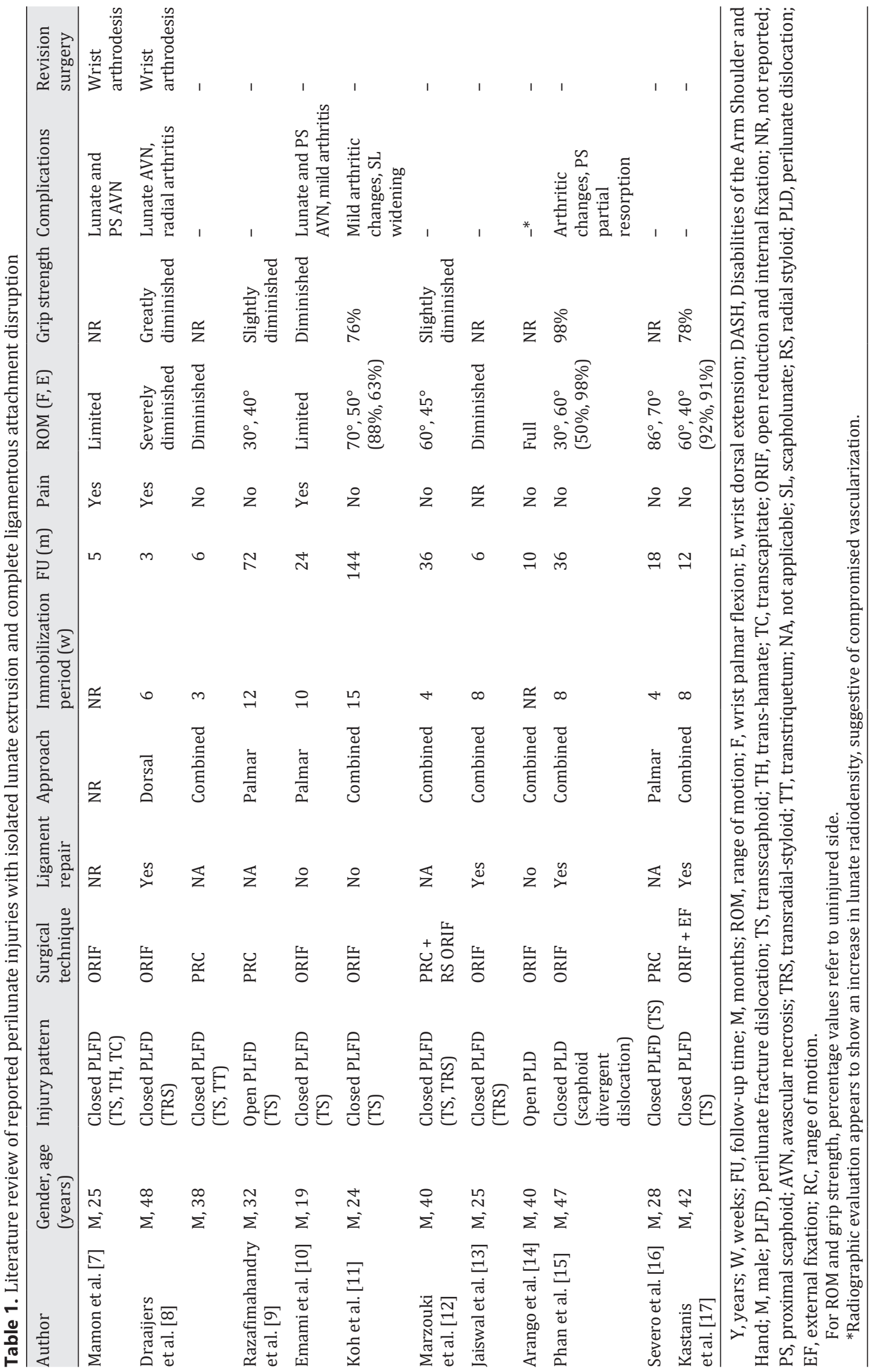


Open injuries amount for 8\% of PLD/PLFD and have a detrimental effect on the overall outcome [5]. Besides the need for initial debridement and antibiotic coverage, treatment of open PLD/PLFD is similar to their closed equivalents, with definitive primary fixation plus ligamentous repair being advised, unless major soft tissue injury is present $[1-3,26,27]$. In the 2 previous reports of open lunate extrusions [9, 14], 1 patient underwent PRC, while the other was subjected to a successful ORIF. As in our case, infectious complications did not occur.

Due to the injury severity of the presented case, ligamentous repair was not possible, and scaphoid fixation revealed unsatisfactory. This led to lunate and scaphoid AVN, with carpal degeneration subsequently developing. Nonetheless, in a short follow-up, our outcomes were consistent with the literature, except for a slightly poorer overall mobility, which improved after hardware removal. Regarding expected outcomes in the literature, Kremer et al. [28] reported an average of $61-63 \%$ and $71 \%$ of contralateral side for mobility and grip strength, respectively. Residual pain can be expected in $20-30 \%$ of patients and reference values for DASH scores are 23-27 [20, 27, 28].

PLFD with lunate extrusion are challenging injuries with a guarded prognosis, even when promptly and adequately treated. The limited number of cases reported start to provide some insights into this unique injury pattern. Though lunate revascularization appears to be possible after an extrusion, the mechanisms for its occurrence are still not understood and its outcome remains unpredictable. Hence, treatment should be decided on an individual basis, considering the expected instability, extent of soft tissue injury, and the surgeon's ability to restore a normal carpus.

\section{Statement of Ethics}

Written informed consent was obtained from the patient for publication of this case report and any accompanying images. The study is exempt from ethical committee approval, according to institutional rules regarding retrospective case reports where patient's anonymity is assured.

\section{Conflict of Interest Statement}

The authors have no conflicts of interest to declare.

\section{Funding Sources}

The authors did not receive any funding.

\section{Author Contributions}

Mário Baptista: design of the work, data acquisition and interpretation, manuscript writing, and final approval. Elisabete Ribeiro: conception of the work, data acquisition and interpretation, manuscript review, and final approval. Melanie Ribau: data acquisition, manuscript review and final approval. Nuno Vieira Ferreira: data acquisition, manuscript review, and final approval. Pedro Varanda: manuscript review, and final approval. Luís Filipe Rodrigues: conception of the work, manuscript review, and final approval.

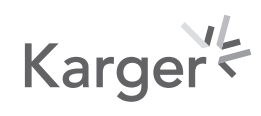




\section{Data Availability Statement}

All data analyzed during this study are included in the article. Further inquiries can be directed to the corresponding author.

\section{References}

1 Kardashian G, Christoforou DC, Lee SK. Perilunate dislocations. Bull NYU Hosp Jt Dis. 2011;69(1):87-96.

2 Sawardeker PJ, Kindt KE, Baratz ME. Fracture-dislocations of the carpus: perilunate injury. Orthop Clin North Am. 2013 Jan;44(1):93-106.

3 Muppavarapu RC, Capo JT. Perilunate dislocations and fracture dislocations. Hand Clin. 2015 Aug;31(3):399-408.

4 Mayfield JK, Johnson RP, Kilcoyne RK. Carpal dislocations: pathomechanics and progressive perilunar instability. J Hand Surg Am. 1980 May; 5(3):226-41.

5 Herzberg G, Comtet JJ, Linscheid RL, Amadio PC, Cooney WP, Stalder J. Perilunate dislocations and fracturedislocations: a multicenter study. J Hand Surg Am. 1993 Sep;18(5):768-79.

6 Gelberman RH, Bauman TD, Menon J, Akeson WH. The vascularity of the lunate bone and Kienböck's disease. J Hand Surg Am. 1980 May;5(3):272-8.

7 Mamon JF, Tan A, Pyati P, Hecht A. Unusual volar dislocation of the lunate into the distal forearm. J Trauma. 1991 Sep;31(9):1316-8.

8 Draaijers LJ, Kreulen M, Maas M. Palmar dislocation of the lunate bone with complete disruption of all ligaments: a report on two cases. Acta Orthop Belg. 2003;69(5):452-4.

9 Razafimahandry HJC, Rakoto-Ratsimba HN, Gille O. Luxation ouverte transscaphorétrolunaire du carpe avec avulsion antébrachiale du semi-lunaire et du fragment scaphoïdien. Chir Main. 2009;28(2):113-5.

10 Emami M, Vadiee I, Namazi H, Vosoughi A. Concomitant flying lunate and scaphoid. J Surg Case Rep. 2011;2011:4.

11 Koh KH, Lim TK, Park MJ. Total volar extrusion of the lunate and scaphoid proximal pole with concurrent scapholunate dissociation. Orthopedics. 2012 Sep 1;35(9):e1427-30.

12 Marzouki A, Almoubaker S, Hamdi O, Laharch K, Boutayeb F. Fracture-luxation trans-scapho-rétrolunaire du carpe avec énucléation antérieure du lunatum et du fragment proximal du scaphoïde. À propos d'un cas. Chir Main. 2013; 32(2):96-9.

13 Jaiswal A, Kachchhap ND, Tanwar YS, Habib M, Kumar B. Complete palmer lunate enucleation: is proximal row carpectomy or wrist arthrodesis the only choice? Chin J Traumatol. 2013;16(5):298-300.

14 Arango D, Tiedeken NC, Ayzenberg M, Raphael J. Open perilunate injury with lunate revascularization after complete ligamentous avulsion. J Surg Case Rep. 2014;2014(5):rju041.

15 Phan KH, Azimi HJ, Franko OI, Abrams RA. Scaphoid and lunate dislocation with complete soft-tissue avulsion: a case report. JBJS Case Connect. 2016;6(3):e58.

16 Severo AL, Lemos MB, Pereira TAP, Fajardo RDP, Maia PEC, Lech O. Trans-scaphoid perilunate fracture dislocation beyond Mayfield stage IV: a case report on a new classification proposal. Rev Bras Ortop. 2018;53(5):643-6.

17 Kastanis G, Velivasakis G, Pantouvaki A, Spyrantis M. An unusual localization of lunate in a transcaphoid volar lunate dislocation: current concepts. Case Rep Orthop. 2019;2019:7207856-5.

18 Berger RA. A method of defining palpable landmarks for the ligament-splitting dorsal wrist capsulotomy. J Hand Surg Am. 2007 Oct;32(8):1291-5.

19 Nattrass GR, King GJ, McMurtry RY, Brant RF. An alternative method for determination of the carpal height ratio. J Bone Joint Surg Am. 1994 Jan;76(1):88-94.

20 Muller T, Hidalgo Diaz JJ, Pire E, Prunières G, Facca S, Liverneaux P. Treatment of acute perilunate dislocations: ORIF versus proximal row carpectomy. Orthop Traumatol Surg Res. 2017;103(1):95-9.

21 Chim H, Moran S. Long-term outcomes of proximal row carpectomy: a systematic review of the literature. Jnl Wrist Surg. 2012;01(02):141-8.

22 Ali MH, Rizzo M, Shin AY, Moran SL. Long-term outcomes of proximal row carpectomy: a minimum of 15-year follow-up. Hand. 2012;7(1):72-8.

23 Wall LB, Didonna ML, Kiefhaber TR, Stern PJ. Proximal row carpectomy: minimum 20-year follow-up. J Hand Surg Am. 2013;38(8):1498-504.

24 Ekerot L. Palmar dislocation of the trans-scaphoid-lunate unit. J Hand Surg. 1995 Aug 29;20(4):557-60.

25 White RE, Omer GE. Transient vascular compromise of the lunate after fracture-dislocation or dislocation of the carpus. J Hand Surg Am. 1984;9(2):181-4.

26 Stanbury SJ, Elfar JC. Perilunate dislocation and perilunate fracture-dislocation. J Am Acad Orthop Surg. 2011 Sep;19(9):554-62.

27 Israel D, Delclaux S, André A, Apredoaei C, Rongières M, Bonnevialle P, et al. Peri-lunate dislocation and fracturedislocation of the wrist: retrospective evaluation of 65 cases. Orthop Traumatol Surg Res. 2016;102(3):351-5.

28 Kremer T, Wendt M, Riedel K, Sauerbier M, Germann G, Bickert B. Open reduction for perilunate injuries: clinical outcome and patient satisfaction. J Hand Surg Am. 2010 Oct;35(10):1599-606. 